\title{
Recognizing Poor Sleep Quality Factors During Oral Health Evaluations
}

\author{
Kelly Schroeder, RDH, MS and JoAnn R. Gurenlian, RDH, MS, PhD
}

\begin{abstract}
Oral health practitioners routinely perform oral health assessments for the dental patient to determine if oral disease is present. Systemic health is often a contributor to oral health concerns. One area in particular that has a direct effect on oral structures and oral health is poor sleep quality and open mouth breathing. Sleep is a fundamental process of the human body, which regulates core biological functions. Sleep quality reflects a person's ability to fall asleep, stay asleep, and enter into the various rejuvenating sleep cycles for the full duration.A person who does not obtain quality sleep can exhibit a wide range of oral, systemic, and cognitive health problems. Obstructive sleep apnea, which historically has been considered an adult male disease, is being recognized more often in women children. Research suggests various oral malformations found in newborns and young children can manifest as obstructive sleep apnea in adults. Oral health professionals are in a position to recognize the relationship between sleep and health, identify sleep quality concerns in relation to oral health assessments, administer sleep quality assessments, and determine appropriate referrals for further sleep quality evaluation.
\end{abstract}

Keywords: Children; Sleep disorders; Integrated health care; Obstructive sleep apnea; Open mouth breathing; Oral disease; Oral health

$\mathrm{O}$ ptimum quality and quantity of sleep regulates our core biological functions. ${ }^{1,2}$ Although the amount of time a person is engaged in sleep is important, reaching the deep rejuvenating stages of sleep is essential for optimum health benefits. ${ }^{1,2}$ Sleep quality reflects how well a person is able to fall asleep, cycle through the various stages of sleep, and stay in those sleep stages for their full duration. ${ }^{1,2}$ Often, manifestations of poor sleep are misinterpreted as behavioral issues, cognitive dysfunction, and/or systemic health concerns that may present differently in children and adults. ${ }^{1,3,4}$ The National Sleep Foundation estimates that 50 to 70 million Americans are affected by chronic sleep disorders or sleep disruptions that can significantly affect health and safety. ${ }^{5}$ The Centers for Disease Control and Prevention (CDC) has declared sleep deprivation a public health crisis. ${ }^{6}$ The key sleep disorders listed by the CDC include insomnia, narcolepsy, restless leg syndrome, and sleep apnea (Table 1). ${ }^{6}$ Sleep deprivation, regardless of the cause, has been shown to cause complex oral, systemic, and cognitive health issues

Corresponding Author: Kelly Schroeder, RDH, MS, Marshfield Clinic Research Institute, Center for Oral and Systemic Health, 1000 North Oak Avenue, Marshfield, WI 54449, Tel: (7I5) 22I-6402, Email: schroeder.kelly@marshfieldresearch. org resulting in poor health-related quality of life and decreased work productivity. ${ }^{15}$

Oral health professionals are in the optimal position to detect a sleep quality concern due to the oral presentation of individuals suffering from chronic poor sleep issues..$^{16,17}$ When poor sleep is suspected, it is the responsibility of oral health clinicians to refer patients to an appropriate allied health professional. ${ }^{18,19}$ The American Dental Association has adopted a formal policy statement that states dentists are to include screening for sleep-related breathing disorders during all oral examinations. ${ }^{18}$ Dentists are also responsible for referring at-risk patients to a primary care provider and work with that provider and the patient to determine the best course of action for that patient. ${ }^{18}$ The American Dental Hygienists' Association also recognizes the dental hygienists' ability and responsibility to identify oral and systemic health relationships and refer patients to the appropriate allied health professional for a patient to obtain optimal health outcomes. ${ }^{19}$ Although

Received: September 23, 2018

Revised: March 25, 2019

Accepted: March 27, 2019

doi: $10.3121 / \mathrm{cmr} .2019 .1465$ 
Table 1. Examples of Sleep Related Conditions and Disorders

\section{Poor Sleep Quality Conditions or Disorders}

Sleep Hygiene

Sleep behavior disorder

Melatonin irregularities

Circadian rhythm disruptions

Insomnia

Narcolepsy

Restless Leg Syndrome

Obstructive Sleep Apnea

\section{Signs, Symptoms or Factors Related to Poor Sleep Quality}

Extrinsic factors such as electronics; blue-light; day-light; disruptions from

people or pets; caffeine; adenosine receptor antagonist medications; sleep position. . $^{1,6,7,8,9}$

Person acts out his or her dreams; includes talking, yelling, punching, jumping from bed, arm flailing and grabbing. ${ }^{6,10}$

Persistent or recurrent patterns of sleep disturbance due to outside factors such as jet lag or shift work. Internal factors such as problems with melatonin release or other abnormalities with the circadian system. ${ }^{2,5,6,11,12}$

Difficulty falling asleep and/or staying asleep for a full sleep cycle. ${ }^{5,6}$

Extreme daytime sleepiness combined with muscle fatigue and weakness. ${ }^{5,6}$

Crawling feeling under skin of lower legs and uncontrollable urge to move legs. Symptoms are usually worse at night. 5,6

Airway collapses during the sleep cycle, preventing normal breathing, causing lack of oxygen to the brain, preventing the individual from reaching deep sleep along with body and brain repair. ${ }^{1,5,6,13,14}$ oral health professionals are providing assessments that can lead to detection of a serious sleep quality concern, shortcomings with identifying sleep disorders in oral health education programs might prevent oral health practitioners from connecting oral health assessments and whole health indictors to a poor sleep quality conclusion. ${ }^{20}$ Even if a sleep quality concern is suspected, there is a general lack of communication and support between medical and dental teams to provide a continuity of care for patients. ${ }^{21,22}$

The oral health assessment process performed by a dentist or dental hygienist is often the first time a sleep quality concern is recognized by a health care provider. Training received by oral health professionals includes obtaining medical and dental histories, identifying abnormal oral structures, detecting oral disease, identifying oral/systemic health links and, more specifically, identifying signs and symptoms of sleep-related bruxism, primary snoring, and obstructive sleep apnea (OSA). ${ }^{19,20}$ Dental providers already provide many medically-related chairside screenings for patients including hypertension, diabetes mellitus, obesity, human papilloma virus, and oral side effects from cancer treatments, with hypertension screening being the most prevelent. ${ }^{23}$ Dental providers report a willingness to conduct medical screenings granted the providers were well trained in the medical condition, screening process, and the screening was time and cost effective. ${ }^{23}$ Early detection of an oral health and systemic health-related condition, such as a sleep disorder or poor sleep condition, has the potential to reduce comorbidities associated with poor sleep health. ${ }^{5,6}$

Poor sleep quality can be a multifactorial situation and/or condition(s) that can be affected by a person's sleep environment, physiological features related to systemic health, oral myofunctional disorders, restricted airway, and/ or chemical and electrical imbalances related to melatonin or circadian rhythm. ${ }^{13,7,8,11,16,24,25}$ Sleep deprivation, including OSA, does not discriminate according to age, gender, or body composition. OSA is not often identified in childhood, because the severity of signs and symptoms tend to increase through developmental growth into adulthood. ${ }^{16,25}$ Research suggests oral structure formation and health concerns can put men, women, and children at risk for a poor sleep situation that needs to be identified and addressed. ${ }^{5,6,11,16,26,27}$

This paper will assist the oral health professional in recognizing the relationship between sleep and health, identifying sleep quality concerns in relation to oral health assessments, disseminating sleep quality assessments, and determining appropriate referrals for sleep quality issues.

\section{Sleep Process}

While sleeping, an individual's mind and body are performing very specific functions that are vital to the regulation, maintenance, and repair of specific body systems. ${ }^{1,2}$ Each of the three non-rapid eye movement (NREM) stages of sleep serve a specific function to quiet body and brain, lower body temperature, and slow heart rate to prepare the body and organ systems for maintenance and repair., ${ }^{1,2}$ The rapid eye movement (REM) stage of sleep allows the mind to transfer new memories and lessons to long-term memory, rationalize emotions, and is vital for brain repair and maturation. ${ }^{1,2} \mathrm{~A}$ quality sleep event includes five to six specific cycles of the various NREM and REM stages over a 7- to 9-hour period. ${ }^{2}$ Each cycle is different from the last and serves a different purpose. ${ }^{2}$ As the sleep event progresses, a person spends more time in REM sleep and less time in the NREM stages. ${ }^{1,2}$ Each time a person experiences a sleep arousal or is pulled 


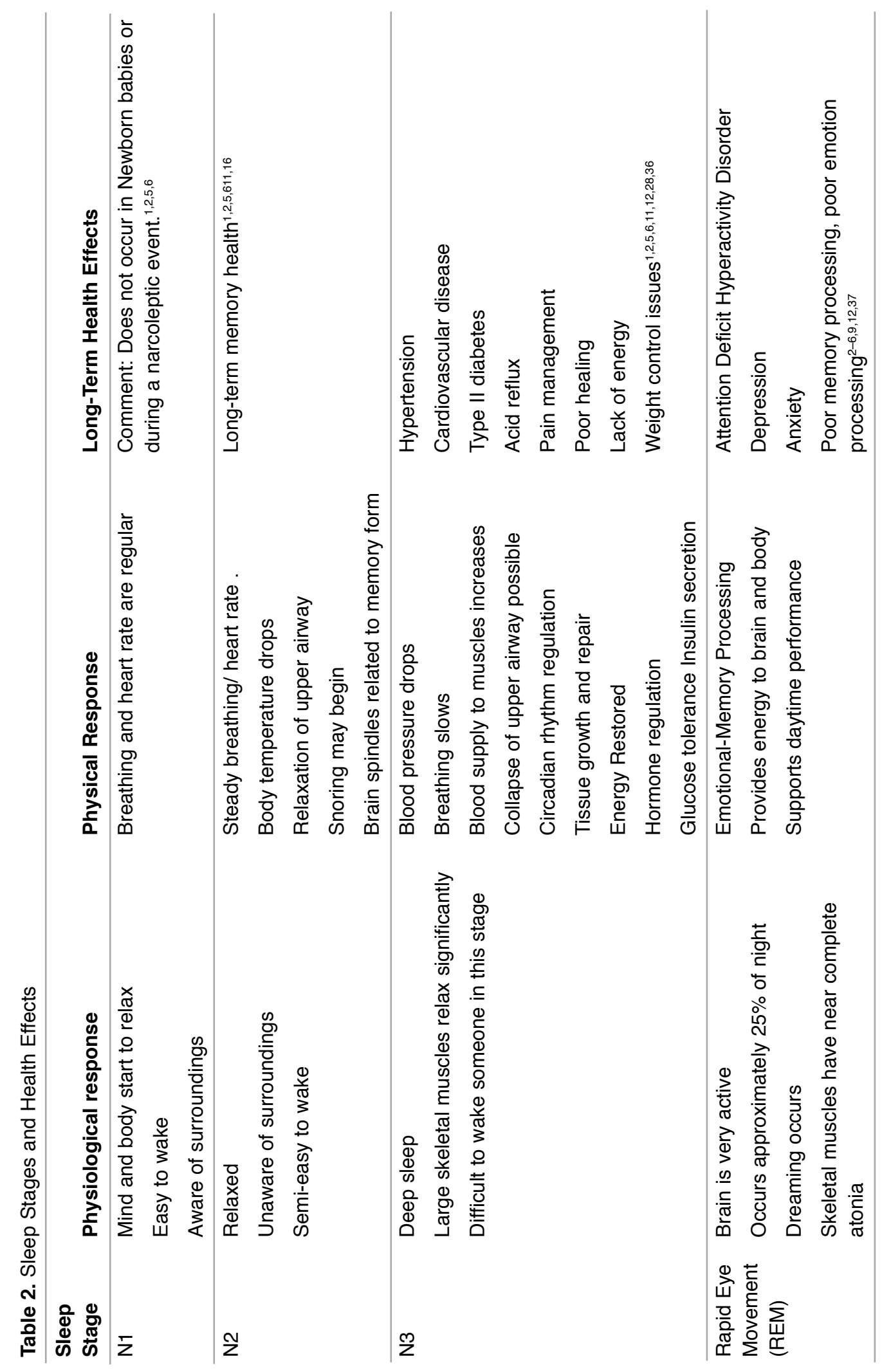


out of the deep stages of sleep, they are prevented from obtaining rejuvenation of the body and brain needed to achieve or maintain optimal health. ${ }^{1,2}$ Sleep arousals can be caused by poor sleep hygiene, restricted airway, systemic health issues, or cognitive health issues. ${ }^{1-4}$

\section{Systemic Health Concerns Related to Poor Sleep}

Due to the role sleep quality has on body and brain repair and rejuvenation many health risks can be factors that either contribute to poor sleep, are caused by poor sleep, and/or are exacerbated by poor sleep. A bidirectional relationship appears to exist between various health concerns and sleep quality. ${ }^{1,11,12,27,28}$ A strong correlation between hypertension, cardiovascular disease, and stroke compared with the quality and quantity of sleep has been consistently shown in literature. ${ }^{29}$ Children who have undiagnosed and untreated sleep disruptions and/or sleep disorders are also at increased risk for hypertension. ${ }^{30}$ Type II diabetes has been shown to have a relationship with chronic sleep arousals. ${ }^{31}$ When an individual is not reaching the N3 stage of sleep or staying in this stage for an adequate amount of time, glucose and insulin regulation is altered. ${ }^{32}$ Obesity has a cyclical relationship with poor sleep quality and hormone and metabolism regulation. ${ }^{32}$ Overweight persons are at a higher risk for airway obstruction upon reaching N3 stages of sleep, resulting in poor regulation of metabolic hormones. ${ }^{28}$ To continue the cycle of poor sleep and obesity, individuals who are sleep deprived are more likely to make unhealthy food choices and consume more calories during the day in an effort to increase energy levels. ${ }^{33}$ Open-mouth breathing, obesity, and poor sleep quality conditions and disorders have been correlated with a higher risk for developing gastroesophageal reflux (GERD) and other esophageal conditions. ${ }^{34}$ Sleep-disordered breathing and asthma have been correlated, as both are inflammatory disorders of the upper and lower airways and can contribute to respective worsening of each condition and possibly lead to OSA. ${ }^{27}$ To make matters more complicated, many of the medications used to treat sleep-related medical conditions contribute to poor sleep due to the type of receptor antagonist effect in the brain. ${ }^{2}$ According to the National Sleep Foundation, medications taken to treat nasal congestion, hypertension, heart disease, thyroid disorders, birth control, breathing issues, and cognitive health concerns can contribute to difficulty with falling and/or staying asleep. ${ }^{5}$

In the past, middle-aged men were mostly likely to be suspected for a poor sleep quality concern; however, researchers now know women are also at equal risk for poor sleep quality concerns as men but for different reasons. ${ }^{26,29}$ Health-related sleep disruptors for women can be related to hormone changes during pregnancy, pregnancy complications, and hormone changes after menopause. ${ }^{26,29}$ Poor sleep factors that affect men, women, and children, such as poor sleep hygiene, systemic health issues (eg, asthma, allergies, obesity), and sleep disorders can exacerbate sleep quality concerns for females. ${ }^{26,29}$
Cognitive Health Concerns Related to Poor Sleep

An individual who is unable to reach the brain repair and rejuvenation stage of sleep called REM is at risk for cognitive health issues. Individuals who are unable to reach and maintain REM sleep have been shown to be at greater risk for attention deficit disorder, bipolar disorder, depression, anxiety, emotion control, cognitive flexibility, and memory processing. Individuals suffering from post-traumatic stress disorder have been shown to have difficulty reaching and maintaining REM sleep, which in turn makes management of this disorder more difficult. ${ }^{4}$ Many other systemic and cognitive health concerns related to poor sleep exist that are beyond the scope of this paper (Table 2).

\section{Oral Health Assessments That Identify Poor Sleep Quality}

Multiple assessments routinely performed by oral health professionals can assist in identifying sleep quality concerns. Temporary or chronic poor sleep quality and/or quantity can be evident in a person's initial general appearance, attitude, and physical ability. Behavioral manifestations such as irritability, impatience, yawning, falling asleep during the appointment, slow body movements, and lack of interest or focus in conversation may all be indicators a patient might be experiencing chronic sleep quality issues. ${ }^{3,4,24}$ Chronic poor sleep quality and/or quantity situations can affect facial feature appearance, the formation of oral structures, and the development of oral disease. , $^{84,25,38-40}$

\section{Health History}

Assessment of a patient's health history includes information such as demographics, social history, medical history, and dental history. ${ }^{19}$ Each piece of information regarding a patient's health, lifestyle, and cultural beliefs can help a health care provider determine the best avenues for ideal health outcomes. Learning about the patient's lifestyle such as type of work, family life, and social life can be indicators of quality of life and sleep quality. Individuals who work a rotating shift or have chronic fragmented sleep tend to have more systemic health issues and make more decision-making errors than those on the standard day shift due to sleep quality disturbances associated with working a rotating schedule..$^{7-9}$

Oral health professionals are trained and qualified to review complex medical histories. ${ }^{19}$ Obtaining a complete and accurate medical history includes noting any health conditions a patient might have along with prescription medications, medicinal supplements, and recreational substances they consume regularly. ${ }^{19}$ Health conditions such as heart disease, diabetes, mental health conditions, cognitive difficulties, and behavioral concerns need to be noted to provide a safe, comfortable, and productive oral care appointment. ${ }^{19}$ Medical histories used in an oral health setting need to include questions surrounding sleep quality, sleep quantity, and previous diagnosis of a sleep condition such as insomnia or OSA. ${ }^{18}$ A patient's dental history can also reveal a history of poor sleep due to how oral structures have formed and wear 
patterns on dentition. A history of orthodontics, missing teeth, clenching/grinding, open mouth breathing, and having a high caries risk can all indicate a poor sleep quality concern when paired with other aspects of the patient's whole health and reports of poor sleep. ${ }^{16,25,38-40}$

\section{Extraoral Examination}

The extraoral examination should be performed at all preventive oral care appointments. This aspect of the oral assessment includes examination of the head and neck for any abnormalities in shape, size, color of the skin, muscle tone, or bony structure development. ${ }^{19}$ Facial features that should alert a health care provider for a sleep quality concern can include flaccid skin tone, recessed chin, short upper lip, open lip posture, open bite, chronic dry lips or excessively wet lips, dried food at the commissures of the lips, long and narrow face, and dark circles under the eyes. ${ }^{16,25}$

\section{Intraoral Examination}

The intraoral examination is also performed at all preventive oral care appointments. This process includes examination of the hard and soft tissues inside the mouth including the gingiva, tongue, buccal mucosa, hard and soft palates, dentition, and oropharyngeal area. ${ }^{19}$ A periodontal assessment includes recording probe depths, which indicates bone loss, gingival attachment loss, and bleeding upon probing. ${ }^{19}$ Radiographs are obtained as needed, according to the American Dental Association guidelines, and also help identify oral disease such as dental decay, compromised periodontium, and other oral maladies. ${ }^{41}$

Research suggests poor tongue placement leading to sleep quality concerns can be traced back to infancy and is strongly linked to an infant's ability to nasal breathe, suck, and swallow. ${ }^{16,25}$ Open mouth breathing and tongue placement is directly related to the formation of the maxilla, sinuses, nasal cavity, and palate. ${ }^{16,25}$ The formation of the oral structures has a direct effect on the ability to breathe, chew, and swallow properly. ${ }^{16,25}$

Additional signs and symptoms relating to poor sleep quality may include structural malformations such as ankyloglossia, enlarged tonsils, malocclusion, and high narrow palate. ${ }^{16,38}$ Ankyloglossia has been shown to be associated with a narrow maxillary inter-canine and intra-molar width resulting in a high narrow hard palate. ${ }^{16}$ Restricted tongue movements, abnormal formation of oral structures, and restricted airway may contribute to poor plaque control, xerostomia or excessive saliva, open mouth posture, and tongue thrust upon swallowing. ${ }^{16,39}$ Macroglossia may indicate the patient is using the tongue to protect the airway while sleeping. ${ }^{16,42}$ Missing teeth or complete edentulism can also cause the tongue to fall back into the airway during wakefulness and sleep states due to the lack of teeth to keep the tongue in proper position if a prosthetic is not worn. ${ }^{38,40}$ Lack of dentition also causes changes in the vertical dimension of the face, thereby affecting the upper airway and retropharyngeal space. ${ }^{38,40}$ Enlarged tonsils that crowd into the airway can contribute to open mouth breathing and ultimately poor sleep quality. ${ }^{16}$ Other oral indicators of open mouth posture and poor sleep quality can include gingivitis, periodontal disease, xerostomia, high caries risk, poor plaque control, poor saliva control, edentulous, or missing teeth. ${ }^{16,38,39,43}$ Seo et $\mathrm{al}^{39}$ reported that in a cross-sectional study, $60 \%$ of participants who were found to have periodontal disease were also diagnosed with OSA. Certain factors that contribute to OSA such as older age, male gender, smoking status, and mouth breathing may also contribute to periodontal disease. ${ }^{39,43}$

Missing teeth and edentulism has also been associated with OSA. ${ }^{40}$ These findings are related to improper tongue placement and the inability to close the lips properly during sleep. ${ }^{40}$ In addition, missing teeth may prevent proper fitting of the continuous positive airway pressure (CPAP) mask during use..$^{40} \mathrm{~A}$ review of the literature surrounding nocturnal wearing of prosthetic and oral appliances to prevent sleep apnea and/or to help a CPAP mask to fit more securely showed that overall positive results were obtained from wearing prosthetic appliances at night for edentulous patients, although there is a need for further studies. ${ }^{40}$

If an obstructed airway is suspected due to large tongue and tonsil size, the Freidman Staging System, which is often used in medical settings to assess airway, is a useful tool to provide a measurable anatomic description to document obstruction..$^{42}$ This system classifies tongue position and tonsil size according to anatomical features visualized when the mouth is open and relaxed. ${ }^{42} \mathrm{~A}$ resting tongue position that covers the mandibular teeth and prevents visualization of the entire oropharynx and soft palate is likely to be contributing to a significant airway obstruction. Likewise, tonsil size and degree of lingual tonsil hypertrophy should be evaluated to determine the degree of airway obstruction. ${ }^{42}$

\section{Screening Tools for Sleep Disruptors.}

The US Preventive Services Task Force does not recommend sleep disorder screening for all patients if signs and symptoms of poor sleep are not exhibited. ${ }^{44}$ After obtaining the medical and dental histories, performing oral assessments, and asking patients about their sleep quality experience, the oral health professional will decide if a poor sleep quality condition exists and if further screening is necessary. If the patient reports chronic loud snoring, gasping for air during sleep, and/or a chronic feeling of tiredness during the day, a sleep assessment tool is in order. ${ }^{45}$

\section{General sleep assessments}

Many sleep quality questionnaires are available online that have been proven valid and reliable. Practitioners are encouraged to use sleep assessment tools as part of a comprehensive evaluation plan incorporating medical history and oral assessments. ${ }^{46}$ Many sleep assessment tools are weighted heavily in favor of the male gender in regards to being at risk for OSA ${ }^{45,47}$ Researchers now know that women 
Table 3. Sleep Quality Assessment Tools

\begin{tabular}{|c|c|c|c|c|c|}
\hline Screening Tool & $\begin{array}{l}\text { Number of } \\
\text { questions }\end{array}$ & Sensitivity & Specificity & Tool target & Population \\
\hline $\begin{array}{l}\text { Epworth Sleep } \\
\text { Scale }^{47-49}\end{array}$ & 8 & $\begin{array}{l}\text { Range } 46 \%- \\
80 \%\end{array}$ & $\begin{array}{l}\text { Range } 75 \%- \\
97 \%\end{array}$ & Daytime sleepiness & Adults \\
\hline $\begin{array}{l}\text { STOP } \\
\text { questionnaire } \\
\text { q7,49 }\end{array}$ & 4 & $100 \%$ & $92.3 \%$ & $\begin{array}{l}\text { Snoring, tiredness, observed } \\
\text { apnea, high blood pressure }\end{array}$ & Adults \\
\hline $\begin{array}{l}\text { STOP-Bang } \\
\text { questionnaire }^{47,49}\end{array}$ & 8 & $95.4 \%$ & $35 \%$ & $\begin{array}{l}\text { Snoring, tiredness, observed } \\
\text { apnea, high blood pressure, age, } \\
\text { neck circumference, gender }\end{array}$ & Adults \\
\hline $\begin{array}{l}\text { Berlin } \\
\text { questionnaire }{ }^{47,49}\end{array}$ & 10 & $97.3 \%$ & $91.7 \%$ & $\begin{array}{l}\text { Snoring, daytime sleepiness, } \\
\text { medical history }\end{array}$ & Adults \\
\hline $\begin{array}{l}\text { Pittsburgh Sleep } \\
\text { Quality } \\
\text { Index(PSQI) }\end{array}$ & 19 & $89.6 \%$ & $86.5 \%$ & General sleep quality & Older adults \\
\hline $\begin{array}{l}\text { Pittsburgh Insomnia } \\
\text { Rating Scale }^{52}\end{array}$ & 65 & $94 \%$ & $94 \%$ & General sleep quality & Adults \\
\hline $\begin{array}{l}\text { Children's Sleep } \\
\text { Habits } \\
\text { Questionnaire }^{53}\end{array}$ & 45 & Low & Low & $\begin{array}{l}\text { General sleep quality and } \\
\text { obstructive sleep apnea }\end{array}$ & Children \\
\hline $\begin{array}{l}\text { Pediatric Sleep } \\
\text { Questionnaire }^{54}\end{array}$ & 44 & $81.6 \%$ & $13.4 \%$ & $\begin{array}{l}\text { Sleep quality for children with } \\
\text { asthma }\end{array}$ & Children \\
\hline
\end{tabular}

and children are also at risk for poor sleep quality for environmental and systemic health reasons. ${ }^{6,16,9,26,29}$ Also, a patient's lifestyle, health history, and oral assessments might indicate a poor sleep condition that is not related to an obstructed airway. ${ }^{6}$ Table 3 lists the most commonly used sleep questionnaires.

\section{OSA assessments}

Paper-based surveys can be beneficial for the initial screening for OSA. Using this type of tool is useful when sending referral information to an allied health professional (Table 4). Several non-invasive, low-cost options are available to conduct initial screenings for OSA for individuals who are not sure if they are experiencing OSA. Sleep applications (Apps), which can be downloaded onto a cellular device, can be used to track and record snoring activity. ${ }^{55}$ Another method to screen for sleep quality is the use of a Fitbit Charge 2. A Fitbit is a device worn on the wrist to record physical activity. ${ }^{56}$ This device has demonstrated utility for assessing sleep and cardiac function in healthy adolescents. ${ }^{56}$ Previous versions of the Fitbit did not demonstrate the same level of reliability and specificity compared to the newer version. More studies are needed to determine if performance of this device is equivalent in individuals with actual OSA. ${ }^{56}$ Depending on a patient's signs, symptoms, and risk factors, a primary care provider might prescribe an in-home sleep test such as the Apnea Link to help determine if further evaluation and treatment for OSA is warranted. ${ }^{57}$ Apnea Link measures airflow through a nasal cannula that is connected to a pressure transducer, allowing the measure of events in which the patient stops breathing during sleep. ${ }^{57}$
For patients who are suspected to have moderate or severe sleep apnea, a polysomnography is often recommended. ${ }^{17}$ This method requires the individual to go to a sleep center or hospital to be observed during the sleep process. ${ }^{17}$ Sensors are placed in specified locations on a patient's head, neck, and chest to record brain activity, muscle tone, and eye movements during the various phases of sleep. ${ }^{2}$

\section{Referral Considerations}

If the oral health professional, along with the patient, has concerns about a sleep quality disorder, further evaluation by a medical provider is recommended. A general health practitioner is an ideal starting point when dealing with the complex issue of sleep quality. As evidence continues to support the need for integrated health care, medical providers have shown an increasing willingness to collaborate with oral health professionals to enhance patient health outcomes. ${ }^{58,59}$ An overall health evaluation by a primary care provider should be undertaken to determine the patient's general state of health before determining if a sleep hygiene, systemic health, or cognitive health concern is contributing to poor sleep and then direct the patient to the proper specialist. A variety of health care providers can support patients with sleep quality concerns including pulmonologists, otolaryngologists, allergists, speech language pathologists, orthodontists, oral myofunctional therapists, and dental professionals who specialize in alternative airway appliances. The American Academy of Dental Sleep Medicine (www.aadsm.org) offers a list of dental sleep medicine specialists by state. 
The referral regarding sleep quality concerns should include the sleep quality assessment tool, patient report of sleep experience, oral assessment risk factors, and documented charting of anatomical considerations including oral features of the tongue, palate, tonsils and facial profile. Quick definitions and graphics such as those supplied by the Friedman Staging System ${ }^{42}$ can be helpful to be sure communication between oral and systemic health professionals is seamless. Intraoral photographs and radiographic images also provide useful resources when diagnosing a sleep related disorder.

\section{Treatment Considerations}

A person at risk for a sleep quality disorder or condition should be informed that the role of the oral health provider is to bring awareness that a sleep quality disorder or condition might exist, provide education regarding the possible concern, refer the person to an appropriate provider, and work with that provider to determine the best treatment options. ${ }^{18,19}$ Motivational interviewing, where the practitioner helps the patient to come to their own solutions for a problem or concern, might be the most effective method for solving sleep hygiene issues. ${ }^{60}$

Several treatment options are available for restricted airway concerns depending on the type of restriction, age, and overall health of the individual. The most common treatment for chronically enlarged tonsils is an adenotonsillectomy or removal of the tonsils. ${ }^{16,25}$ A surgical procedure alone does not necessarily restore normal nasal breathing during sleep; ${ }^{16,25}$ however, in some cases, tonsil removal along with oral myofunctional therapy has been shown to produce more positive results in achieving improved sleep quality. ${ }^{16,17}$ Oral myofunctional therapy, which consists of specific exercises to strengthen and retrain the tongue, soft palate, and pharyngeal walls, may be an effective adjunct in OSA therapy and was shown to reduce the apnea-hypopnea index by $30 \%-40 \%$ in adults. ${ }^{17}$ Exercises to strengthen the muscles of the face and improve tongue placement in the oral cavity can contribute to a decrease in snoring, improvement in daytime sleepiness, improvement in polysomnography results, and improved blood oxygen saturation. ${ }^{17}$

Treatment of OSA often includes the use of a CPAP device, which forces air through a face mask or nasal cannula worn on the patient's face to keep the airway open during sleep. ${ }^{17,61}$ This is the most effective method for preventing apneic events during sleep, but the compliance rate for continuous use of a CPAP is low. ${ }^{17,61}$ Improved quality of life and health was reported in several studies in conjunction with long-term use of a CPAP machine in those with moderate to severe OSA. ${ }^{13,61}$ For individuals diagnosed with mild to moderate OSA, a mandibular advancement device, made by a dentist, was found to have similar effectiveness as a CPAP device, possibly due to the higher compliance rate..$^{17,18,61}$
Other treatment options for patients with OSA might include surgical procedures such as frenectomy, orthodontia, and adenotonsillectomy. ${ }^{16,25,38}$ Patients should be made aware that multiple options are available for treating obstructive airway, and more than one treatment modality may be indicated based on their severity of OSA, head and neck anatomy, and ability to tolerate various interventions. ${ }^{17}$

At each continuing care appointment, the oral health professional should document all concerns and actions taken to remedy sleep quality concerns. Further sleep quality care will be determined along with the primary care provider, oral health provider, and patient once newly performed oral health assessments have been performed upon the implementation of sleep quality interventions. ${ }^{18,19}$

\section{Conclusion}

Sleep deprivation has become a national health crisis affecting individual health, safety, and quality of life. There are many different reasons for sleep deprivation including poor sleep hygiene, systemic health issues, and sleep disorders. Most people who suffer from daytime sleepiness are not aware that poor sleep is affecting long-term and short-term health. The training, expertise, and unique patient interactions between the patient and oral health care practitioners lends to feasibility of systemic health findings during oral health assessments. Sleep quality is an important component of oral health and systemic health, which requires integrated health care teams. Upon gathering information about a patient's oral and systemic health, the oral health practitioner must be able to recognize that a problem exists and be willing to provide additional assessments, such as administering a sleep quality questionnaire, and then refer the patient to an appropriate allied health care professional. Clear and concise communication between the oral health practitioner, the patient, and the allied health professional is imperative and can be improved by having written and detailed referral letters and additional pertinent information regarding the health concern. As primary providers of health care to our patients, oral health professionals have the ability to help patients achieve optimal oral and systemic health and improved quality of life. With the implementation of quality research demonstrating the inseparable relationship between oral and systemic health, oral health care and medical systems are encouraged to work together to provide a continuity of care for consumers.

\section{References}

1. Koo DL, Nam H, Thomas RJ, Yun CH. Sleep Disturbances as a Risk Factor for Stroke. J Stroke. 2018;20(1):12-32.

2. Carley DW, Farabi SS. Physiology of Sleep. Diabetes Spectr. 2016;29(1):5-9.

3. Wynchank D, Bijlenga D, Beekman AT, Kooij JJS, Penninx BW. Adult Attention-Deficit/Hyperactivity Disorder (ADHD) and Insomnia: an Update of the Literature. Curr Psychiatry Rep. 2017;19(12):98.

4. Murkar ALA, De Koninck J. Consolidative mechanisms of emotional processing in REM sleep and PTSD. Sleep Med Rev. 2018;41:173-184. 
5. National Sleep Foundation. Sleep Topics. Sleep Studies. Available at: https://www.sleepfoundation.org/sleep-topics. Accessed March 20, 2019.

6. Centers for Disease Control and Prevention. Sleep and Sleep Disorders. Available at: https://www.cdc.gov/sleep/about sleep/key_disorders.html. Accessed March 21, 2019.

7. Nagashima S, Osawa M, Matsuyama H, Ohoka W, Ahn A, Wakamura T. Bright-light exposure during daytime sleeping affects nocturnal melatonin secretion after simulated night work. Chronobiol Int. 2018;35(2):229-239.

8. Cho $\mathrm{CH}$, Lee HJ, Yoon HK, et al. Exposure to dim artificial light at night increases REM sleep and awakenings in humans. Chronobiol Int. 2016;33(1):117-123.

9. Honn KA, Hinson JM, Whitney P, Van Dongen HPA. Cognitive flexibility: A distinct element of performance impairment due to sleep deprivation. Accid Anal Prev. 2018;(March) :S0001-4575(18)30070-8.

10. Haba-Rubio J, Frauscher B, Marques-Vidal P, et al. Prevalence and determinants of rapid eye movement sleep behavior disorder in the general population. Sleep (Basel). 2018;41(2).

11. Chang YS, Chiang BL. Mechanism of Sleep Disturbance in Children with Atopic Dermatitis and the Role of the Circadian Rhythm and Melatonin. Int J Mol Sci. 2016;17(4):462.

12. Melo MCA, Garcia RF, Linhares Neto VB, et al. Sleep and circadian alterations in people at risk for bipolar disorder: A systematic review. J Psychiatr Res. 2016;83:211-219.

13. Batool-Anwar S, Goodwin JL, Kushida CA, et al. Impact of continuous positive airway pressure (CPAP) on quality of life in patients with obstructive sleep apnea (OSA). J Sleep Res. 2016;25(6):731-738.

14. Luyster FS. Impact of Obstructive Sleep Apnea and Its Treatments on Partners: A Literature Review. J Clin Sleep Med. 2017;13(03):467-477.

15. Stepnowsky C, Sarmiento KF, Bujanover S, Villa KF, Li VW, Flores NM. Comorbidities, Health-Related Quality of Life, and Work Productivity Among People With Obstructive Sleep Apnea With Excessive Sleepiness: Findings From the 2016 US National Health and Wellness Survey. J Clin Sleep Med. 2019;15(02):235-243.

16. Guilleminault C, Huang YS. From oral facial dysfunction to dysmorphism and the onset of pediatric OSA. Sleep Med Rev. 2018;40:203-214.

17. Lorenzi-Filho G, Almeida FR, Strollo PJ. Treating OSA: Current and emerging therapies beyond CPAP. Respirology. 2017;22(8):1500-1507.

18. American Dental Association. Council on Dental Practice Dentistry's Role in Sleep Related Breathing Disorders. Available at: https://www.ada.org/en/member-center/ leadership-governance/councils-commissions-andcommittees/dentistry-role-in-sleep-related-breathingdisorders. Accessed March 20, 2019.

19. American Dental Hygienists' Association. Standards for Clinical Dental Hygiene Practice Revised 2016 Supplement. Available at: https://www.adha.org/resources-docs/2016-RevisedStandards-for-Clinical-Dental-Hygiene-Practice.pdf. Accessed March 20, 2019.

20. Minichbauer BC, Sheats RD, Wilder RS, Phillips CL, Essick GK. Sleep medicine content in dental hygiene education. J Dent Educ. 2015;79(5):484-492.

21. Halasa Y, Doonan M. Issue Brief. 2016. Integrating Oral and General Health: The Role of Accountable Care Organizations. Available at: https://masshealthpolicyforum.brandeis.edu/ forums/Documents/Oral Health 2016/Integrating Oral Health into ACOs_Final Issue Brief.pdf. Accessed March 14, 2019.
22. Atchison KA, Rozier RG, Weintraub JA. Integrating Oral Health, Primary Care, and Health Literacy: Considerations for Health Professional Practice, Education and Policy. Available at: http://nationalacademies.org/hmd/ /media/Files/Activity Files/PublicHealth/HealthLiteracy/Commissioned Papers -Updated 2017/Atchison K et al 2017 Integrating oral health primary care and health literacy.pdf. Accessed March 14, 2019.

23. Shimpi N, Schroeder D, Kilsdonk J, Chyou PH, Glurich I, Acharya A. Assessment of Dental Providers' Knowledge, Behavior and Attitude towards Incorporating Chairside Screening for Medical Conditions: A Pilot Study. Journal of Dental and Oral Care Medicine. 2016;2(1):102. doi:10.15744/2454-3276.2.102

24. Almoznino G, Haviv Y, Sharav Y, Benoliel R. An update of management of insomnia in patients with chronic orofacial pain. Oral Dis. 2017;23(8):1043-1051.

25. Lee SY, Guilleminault C, Chiu HY, Sullivan SS. Mouth breathing, "nasal disuse," and pediatric sleep-disordered breathing. Sleep Breath. 2015;19(4):1257-1264.

26. Jehan S, Auguste E, Zizi F, et al. Obstructive Sleep Apnea: Women's Perspective. J Sleep Med Disord. 2016;3(6):1064. http://www.ncbi.nlm.nih.gov/pubmed/28239685. Accessed March 20, 2019.

27. Sánchez T, Castro-Rodríguez JA, Brockmann PE. Sleepdisordered breathing in children with asthma: a systematic review on the impact of treatment. J Asthma Allergy. 2016;9:83-91. doi:10.2147/JAA.S85624.

28. Leproult R, Van Cauter E. Role of sleep and sleep loss in hormonal release and metabolism. Endocr Dev. 2010;17:1121.

29. Zhou J, Zhang J, Li Y, et al. Gender differences in REM sleep behavior disorder: a clinical and polysomnographic study in China. Sleep Med. 2015;16(3):414-418.

30. Nisbet LC, Yiallourou SR, Biggs SN, et al. Preschool children with obstructive sleep apnea: the beginnings of elevated blood pressure? Sleep (Basel). 2013;36(8):1219-1226.

31. Pamidi S, Tasali E. Obstructive sleep apnea and type 2 diabetes: is there a link? Front Neurol. 2012;3:126.

32. Doumit J, Prasad B. Sleep Apnea in Type 2 Diabetes. Diabetes Spectr. 2016;29(1):14-19.

33. Kruger AK, Reither EN, Peppard PE, Krueger PM, Hale L. Do sleep-deprived adolescents make less-healthy food choices? Br J Nutr. 2014;111(10):1898-1904.

34. Lindam A, Kendall BJ, Thrift AP, Macdonald GA, O'Brien S, Lagergren J, Whiteman DC. Symptoms of Obstructive Sleep Apnea, Gastroesophageal Reflux and the Risk of Barrett's Esophagus in a Population-Based Case-Control Study. PLoS One. 2015;10(6):e0129836.

35. Dinis J, Bragança M. Quality of Sleep and Depression in College Students: A Systematic Review. Sleep Sci. 2018;11(4):290-301.

36. Chen Q, Hayman LL, Shmerling RH, Bean JF, Leveille SG. Characteristics of chronic pain associated with sleep difficulty in older adults: the Maintenance of Balance, Independent Living, Intellect, and Zest in the Elderly (MOBILIZE) Boston study. J Am Geriatr Soc. 2011;59(8):1385-1392.

37. Berson SR, Klimczak J, Prezio EA, Hu S, Abraham M. Clinical associations between allergies and rapid eye movement sleep disturbances. Int Forum Allergy Rhinol. 2018;8(7):817-824.

38. Huynh NT, Emami E, Helman JI, Chervin RD. Interactions between sleep disorders and oral diseases. Oral Dis. 2014;20(3):236-245.

39. Seo WH, Cho ER, Thomas RJ, et al. The association between periodontitis and obstructive sleep apnea: a preliminary study. J Periodontal Res. 2013;48(4):500-506.

40. Heidsieck DSP, de Ruiter MHT, de Lange J. Management of obstructive sleep apnea in edentulous patients: an overview of the literature. Sleep Breath. 2016;20(1):395-404. 
41. American Dental Association. Dental Radiographic Examinations: Recommendations for Patient Selection and Limiting Radiation Exposure Revised: 2012 American Dental Association Council on Scientific Affairs. Available at: https://www.ada.org/ /media/ADA/Member\%20Center/FIles/ Dental_Radiographic_Examinations_2012.pdf. Accessed March 21, 2019.

42. Friedman M, Salapatas AM, Bonzelaar LB. Updated Friedman Staging System for Obstructive Sleep Apnea. Adv Otorhinolaryngol. 2017;80:41-48.

43. Ahmad NE, Sanders AE, Sheats R, Brame JL, Essick GK. Obstructive sleep apnea in association with periodontitis: a case-control study. J Dent Hyg. 2013;87(4):188-199. http:// www.ncbi.nlm.nih.gov/pubmed/23986412. Accessed March 20, 2019.

44. Bibbins-Domingo K, Grossman DC, Curry SJ, et al; US Preventive Services Task Force. Screening for Obstructive Sleep Apnea in Adults. JAMA. 2017;317(4):407-414.

45. Abrishami A, Khajehdehi A, Chung F. A systematic review of screening questionnaires for obstructive sleep apnea. Can J Anesth. 2010;57(5):423-438. doi:10.1007/s12630-0109280-x.

46. Owens JA, Spirito A, McGuinn M. The Children's Sleep Habits Questionnaire (CSHQ): psychometric properties of a survey instrument for school-aged children. Sleep. 2000;23(8):1-9.

47. Amra B, Rahmati B, Soltaninejad F, Feizi A. Screening Questionnaires for Obstructive Sleep Apnea: An Updated Systematic Review. Oman Med J. 2018;33(3):184-192.

48. The Epworth Sleepiness Scale Official Website. Johns M. About the ESS. Available at: http://epworthsleepinessscale. com/about-the-ess/. Accessed March 21, 2019.

49. Chiu HY, Chen PY, Chuang LP, et al. Diagnostic accuracy of the Berlin questionnaire, STOP-BANG, STOP, and Epworth sleepiness scale in detecting obstructive sleep apnea: A bivariate meta-analysis. Sleep Med Rev. 2017;36:57-70.

50. Manzar MD, Moiz JA, Zannat W, et al; Ahmed S. BaHammam. Validity of the Pittsburgh Sleep Quality Index in Indian University Students. Oman Med J. 2015;30(3):193-202.

51. University of Pittsburgh. Sleep and Chronobiology Center. Pittsburgh Sleep Quality Index (PSQI). Available at: https:// www.sleep.pitt.edu/research/instruments.html. Accessed March 20, 2019.

52. Veqar Z, Hussain ME, Moiz JA. Psychometric analysis of the Pittsburgh insomnia rating scale among university population of poor sleepers in India. N Am J Med Sci. 2014;6(4):161167.

53. Markovich AN, Gendron MA, Corkum PV. Validating the Children's Sleep Habits Questionnaire Against Polysomnography and Actigraphy in School-Aged Children. Front Psychiatry. 2015;5:188.

54. Ehsan Z, Kercsmar CM, Collins J, Simakajornboon N. Validation of the pediatric sleep questionnaire in children with asthma. Pediatr Pulmonol. 2017;52(3):382-389.

55. American Sleep Association. Snoring Apps - Research \& Reviews. Available at: https://www.sleepassociation.org/ sleep-disorders/snoring-solutions/snoring-apps/. Accessed March 21, 2019.

56. de Zambotti M, Goldstone A, Claudatos S, Colrain IM, Baker FC. A validation study of Fitbit Charge $2^{\mathrm{TM}}$ compared with polysomnography in adults. Chronobiol Int. 2018;35(4):465476.

57. Erman MK, Stewart D, Einhorn D, Gordon N, Casal E. Validation of the ApneaLink for the screening of sleep apnea: a novel and simple single-channel recording device. J Clin Sleep Med. 2007;3(4):387-392. http://www.ncbi.nlm.nih.gov/ pubmed/17694728. Accessed March 21, 2019.
58. Shimpi N, Bharatkumar A, Jethwani M, et al. Knowledgeability, Attitude and Behavior of Primary Care Providers Towards Oral Cancer: a Pilot Study. J Cancer Educ. 2018;33(2):359-364.

59. Shimpi N, Schroeder D, Kilsdonk J, et al. Medical Providers' Oral Health Knowledgeability, Attitudes, and Practice Behaviors: An Opportunity for Interprofessional Collaboration. J Evid Based Dent Pract. 2016;16(1):19-29.

60. Bray KK, Catley D, Voelker MA, Liston R, Williams KB. Motivational interviewing in dental hygiene education: curriculum modification and evaluation. J Dent Educ. 2013;77(12):1662-1669. http://www.ncbi.nlm.nih.gov/ pubmed/24319138. Accessed March 23, 2019.

61. Doff MH, Hoekema A, Wijkstra PJ, et al. Oral appliance versus continuous positive airway pressure in obstructive sleep apnea syndrome: a 2-year follow-up. Sleep. 2013;36(9):12891296.

\section{Author Affiliations}

Kelly Schroeder, RDH, MS* and JoAnn R. Gurenlian, RDH, $M S, P h D^{\dagger}$

\author{
*Dental Hygienist-Researcher, Marshfield Clinic Research \\ Institute, Center for Oral and Systemic Health, Marshfield, \\ Wisconsin, USA \\ $†$ Professor and Graduate Program Director, Department of \\ Dental Hygiene, Idaho State University, Pocatello, Idaho, \\ USA
}

